\title{
Significance of Different Dietary Habits in Sections of Indian Diabetics
}

\author{
A. Mitra ${ }^{1}$, B. Basu' ${ }^{2}$ and S. Mukherjee ${ }^{3}$ \\ 1 \& 3. School of Medical Science and Technology, Indian Institute of Technology, \\ Kharagpur 721302, West Bengal, India \\ Telephone: 091-03222-282220, Fax: 091-03222-282221 \\ E-mail: amitra@smst.iitkgp.ernet.in \\ 2. Calcutta National Medical College, Kolkata, West Bengal, India
}

KEYWORDS Diabetes. Diet. Dyslipidaemia. Indian Subcontinent

\begin{abstract}
Prevalence of Insulin Resistance syndrome particularly Type 2 diabetes along with dyslipidaemia is increasing at an explosive rate in Indian subcontinent. Exact cause, which leads to Type 2 diabetes, is unknown and many factors are believed to play their parts in the pathogenesis of the disease. Genetic predispositions, faulty dietary patterns and sedentary life-styles are indicated by researchers as important factors leading to the increase in prevalence. A review of literature shows that different varieties of food when taken as per recommendations of American Diabetes Association and a proper life-style pattern reduces the incidence of diabetes with dyslipidaemia. This is particularly important in a country like India where available health infrastructures particularly in its rural sectors are deficient.
\end{abstract}

\section{INTRODUCTION}

\section{Prevalence of Diabetes in India}

As per King et al. (1998) prevalence of diabetes in India will increase by 195\% in 2025 and majority of sufferers will be young. Type 2 diabetes along with its fore-runner, that is, Impaired Glucose Tolerance (IGT) are results of Insulin Resistance (IR) commonly associated with Obesity, Hypertension, Coronary Artery Disease (CAD) and Dyslipidaemia.

The disease is affecting at an alarming rate to both rural and urban populations in India (Ramachandran et al. 1990 and 2001; Mohan et al. 2001 and 2006). The first systematic nationwide study in India was performed by the Indian Council of Medical Research Task Force on diabetes. This study used a uniform methodology and sampling techniques and was performed at six centres in the country. Population sampling in urban areas was based on stratified random design and in rural areas on cluster sampling. In large cities in north and south India (Chennai, Trivandrum, Mumbai, Delhi, Jaipur and Gauhati as well as a national study in large metropolises, and industrial populations, diabetes prevalence among adults (e"20 years) had ranged from 8$15 \%$. The prevalence of diabetes was more on the Southern parts of the country and was least in the Eastern parts. The prevalence of diabetes had increased in Hyderabad with an average of
16.5 per cent above the age of 25 suffering from the disease as compared to near about five per cent in some other cities in India and world average of three percent. However, in rural areas the prevalence was five per cent less. The Diabetes Awareness Survey in Hyderabad (DASH) study conducted in the twin cities has recently pointed out that the Diabetes prevalence levels have grown significantly from 16.6 per cent as per the National Urban Diabetes Survey (NUDS) of 2001. Exact reason for the growing prevalence rate of Diabetes in Hyderabad was not yet ascertained. The DASH study had revealed that nearly 43 per cent of the Hyderabad population was unaware of a condition called Diabetes and 65 per cent did not know that Diabetes could affect the eyes, which could lead to decreased sight. The increased prevalence of Diabetes in India has a lot to do with a switch from a traditional to a Western diet and lifestyle patterns and cultural mix (http: //news.webindia 123.com/news/showdetails.asp? $\mathrm{id}=231251$ \&cat= Health).

\section{Role of Diet}

Diet had a profound role in the control of insulin resistant syndrome (Raheja et al. 1970; Sanders et al. 1985; Ghafoarunissa 1996; Luscombe et al. 2002; Mitra and Bhattacharya 2005 and 2006a).

Mitra and Bhattacharya (2005 and 2006b) found while rural diet was diabetogenic in nature, 
increase in protein content in the diet was easier to comply and more satiating. It caused reduction of abdominal fat in males. This corroborated with the observations of Luscombe et al. (2002). Ghafoarunissa (1996) observed that in Indian rural diet, fat intake, particularly intake of omega-3 fatty acid was low and intake of fat was directly proportional to income. Sanders et al. (1985) showed that with a low fat intake the difference in effects of omega- 3 and omega- 6 fatty acids were marginal. Hence, the view expressed by Sanders et al. was contrary to the view expressed by Raheja et al. (1970) who linked the diabetic explosion in India, to increase in consumption of omega-6 fatty acids which started from mid 70 s in order to reduce blood cholesterol levels and subsequent coronary artery diseases.

Ornish (1996) had advocated that a low fat diet was beneficial for health but it had the disadvantage of low HDL level in blood. Hence, a diet with adequate fat and with omega- 3 and omega-6 fatty acids was good for health. It was observed that vegetarian diet had a role in reducing the incidence of IR (Burslem et al. 1978; Burr and Sweetman 1982; Ernst et al. 1986; Fisher et al. 1986).

\section{Diet in Selective Parts of India}

Southern Indian populace is rice-eating and eats preparations made from rice for all the meals during the day. Lentils too are consumed extensively, as accompaniment to the rice preparations. Being on the seacoast, coconut is also being used a lot in kitchens, as are fish and other seafood. While tamarind is used for adding the distinctive taste, peppercorns and chili, both green and red, are used to make the food hot. To neutralize the effect of the chili, and soothe the stomach, curd is used in a variety of dishes. Other spices like mustard, cumin, garlic etc. are used for tempering and seasoning. Though several communities in the state are strictly vegetarian, there is a whole range of non-vegetarian dishes - exotic, succulent, and full of fire. Fish and other seafood like crab are also cooked in the traditional Tamil kitchen with spices and traditional seasoning. In Southern parts of India, food has a ritual purpose that reminds the individual exactly where he or she belongs on the culinary map of community consciousness. This is best seen during those occasions when members of any family or community get together to celebrate an occasion (http: //www.kuttyjapan.com/tamilrecipes/ idly.asp). Region-wise analysis showed a high prevalence of Diabetes Mellitus in the Andhra and Rayalaseema regions where rice is traditionally consumed more, Hypertension in the Andhra region, and Smoking in the Rayalaseema region. Lipid disorders were equally prevalent in all the regions (Reddy et al. 2002). In Karnataka and Kerala dietary habits are slightly different from Tamils and Telugus. The impingement of western culture to the traditional is less. Cooking patterns are different and sedentary activities are less. It has been reported that the incidence percentage of Diabetes Mellitus and Cancer in India, parallel each other. However, it is being observed that a low incidence of Diabetes Mellitus patients also having cancer in south Karnataka. Though the exact reason for this remains unclear. An attempt has been made here to explain this phenomenon, hypothetically using information in literature, which suggests a suppression of cellular regenerative activity (Maliyannar and Shrinivas 2004). Kerala is facing a huge challenge these days in the form of growing incidence of Diabetes. Kerala has now begun a unique campaign in the capital of Kerala, in the wake of acquiring the dubious status of being the epicenter of the country's diabetic population. Some estimates say close to Rs 50,000 million are spent each year to treat Diabetes in the state, whose annual budget is just a little higher at Rs 56,000 million (http: //www.mykerala.com/n/health.shtml). Despite a fast proliferating diabetic population, Governmental efforts in dealing with it continue to be dismal and target lacking (http: //www.dailyexcelsior. com/01may07/inter.htm). According to the fiveyear long study of the Department of Community Medicine at the PGI, Chandigarh, being conducted from 1995 to 2000, 6 per cent of the males in the city, between 35 to 54 years of age suffer from Diabetes while the 5 per cent of the females in the city in the same age group are diabetic and above 55 yrs $11 \%$ of male and $13 \%$ of females are diabetic. One of the main reasons for proliferating diabetic cases is the sedate lifestyle, in take of junk food, obesity and inactive routine. Unhealthy eating with increasing dependence on the "energy dense food" or simply put the junk food, is the main reason for increasing lifestyle ailments in the city. Statistics, however, prove the deplorable eating patterns in the city. As high as 51 per cent of the city's population 
rely on fried food (paranthas) in their daily diet, (as compared to nearby township area $43 \%$ and two per cent less in villages). Physical inactivity is found in $50 \%$ of both male and female, 28 per cent in the age group of 35 to 54 years and 17 per cent above the age of 55 years are regular smokers and more than 40 per cent of the city's adult population consumes alcohol regularly (Chandigarh Tribune 2005).

\section{Different Factors Leading to Diabetes in Indians}

While most people get Diabetes if their bodymass index is 30-31, in the case of Indians, a bodymass index of above 25 is enough for them to get Diabetes. The ideal body mass index by international standards is 25 and below, but the ideal for an Indian should be 23 and below. Only five per cent of the surveyed individuals know that sedentary lifestyle is a risk factor for Diabetes. Sedentary lifestyle, genetic susceptibility, environmental and lifestyle changes resulting from industrialization and migration to urban environment from rural settings may be responsible for high incidence of the disease. Compared to the Chinese, the Europeans, or the Koreans, urban Indians do not have the habit of exercising. Indians, frankly, prefer sitting in front of the television rather to taking a walk (http: // news.hitavadaonline.com/news/index.php? mode $=$ single $\&$ page $=11 \& n=6546$ ). Inter-population differences exist in both diet and the sociocultural factors both within and outside the subcontinent. Available data suggest that diet is the main culprit. Type 2 Diabetes prevalence rates are higher in the east coast of Andhra Pradesh, particularly in Eluru and Tenali where rice is traditionally consumed as only cereal. The prevalence rate in urban and rural Hyderabad is low because of the presence of mainly wheat eating communities. The dietary pattern, eating and methods of cooking vary in different parts of India (Ramaiya et al. 1990). Mitra and Bhattacharya (2005, 2006a) found that diet has a role to play in the prevalence of Type 2 Diabetes and the condition improves with diet prescribed as per American Diabetes Association (ADA) guidelines (ADA 1987) However, with migration, the traditional dietary pattern changes rapidly with an increase in the consumption of "modern" foods coping with the West where changes in dietary adjustments has extended over many generations leading to genetic adjustments. Traditionally, Hindu Indians are pure vegetarians, but with modernization the diet has become more lacto-vegetarian. In addition to the use of meat, fish, and poultry with moderate use of eggs, dairy products, with a relatively high intake of vegetables oils. Hence the intake is of more polyunsaturated fat (Mitra and Bhattacharya 2006a). Some workers believe that a vegetarian diet reduces the risk of developing Diabetes but in a multi-center Indian study Diabetes was more prevalent in vegetarians $(2.1-2.8 \%)$ than in nonvegetarians $(<2 \%)$. In Tanzania, Hindu Indians, majority of who are vegetarians also had a higher prevalence of Diabetes than Muslim Indians who are non-vegetarians. Asian Indians living in America maintaining Indian dietary habits have higher insulin levels, higher plasma glucose levels and lower insulin binding to erythrocytes after a glucose load than Caucasoid Americans, suggesting an increased risk of developing Type 2 Diabetes, though the risk reduces in $2^{\text {nd }}$ generation of American Indians (Ramaiya et al. 1990). The contribution of diet, therefore, to the increased prevalence of Diabetes in Asian Indians is still hazy and more nutritional studies are required to know the specific contribution of diet, independent of obesity to the pathogenesis of Type 2 Diabetes. WHO Expert Committee (2002) opined that under-nutrition protects populations against Diabetes and as under-nutrition is common in India, incidence and prevalence of Diabetes should be less in Indians, but on the contrary, it is more. Indian lifestyle habits, especially diet, might be invoked to explain the increased susceptibility to glucose intolerance based on Neel's thrifty genotype hypothesis and Dilman's theory of failure in adaptosis mechanism (Dilman 1989). Since then attempts have been made to assess the role of diet to Diabetes in population surveys. Diet may contribute to the development of Diabetes in two ways: quantitatively, by supplying calories and if activity is low by resultant obesity and qualitatively by the effects of specific foods. The long term effects of intermittent starvation and the pathological metabolic stress consequent to it on the course of glucose tolerance are not known still yet though some populations in India, where prevalence of Diabetes on higher side (tribal belts of Rajasthan and Gujrat) consume very little protein on some days and an alternate starvation-excess cycle exists (Ramachandran et al. 1990).

While it is possible that some of these factors 
are either racially or genetically predetermined (Mohan et al. 1996; Misra et al. 2001; Harris et al. 2002), prime factor for the increase could be the adverse life style patterns (Ramachandran et al. 2003).

The results of a long follow-up of children from birth to 30-35 years have brought out certain factors during early childhood that lead to Diabetes in later life. In a meticulous analysis of the children whom they followed from birth through their early adulthood, the researchers found that heavy mothers give birth to bigger babies who later on become obese adults. They also found that, paradoxically, the babies who have a low birth weight tend to grow rapidly in childhood and become obese adults. This phenomenon is already noticeable in the developing countries where with availability of better nutrition, particularly for boys, there are sudden spurts of growth leading to obesity, which in turn is an important factor in the development of Diabetes. The critical period of growth for the children is early childhood and indeed even earlier than that, the intrauterine life. These observations point towards the possibility of intervention during these phases of life, which makes more economic and medical sense than developing drugs for Diabetes. The fasting glucose level in the children was not high to begin with but stressing the system by giving higher dose of glucose brings out the presence of Diabetes. The efforts need to start during the intrauterine life, early childhood and adolescent life. An enormous effort to educate the community is needed. Infants who are at the highest end of the distribution for weight or body mass index or who grow rapidly during infancy is at increased risk of subsequent obesity (Baird et al. 2005). No wonder the WHO has declared the year 2002 as the year of Lifestyle Changes (Anonymous 2002). Stress as a result of faulty life-style may lead to more of visceral obesity and increase in waist circumference leading to increase in Insulin Resistance (Wahrenberg et al. 2005). This rising trend predicts a significant health burden due to Diabetes in India. This problem started developing in the childhood more in the urban areas where children do not have any kind of physical exercise and consequently the life-style pattern is altered. The only things one do is to spend long hours on the computer or the cell phone or watch television (http: //www. chennaionline.com/health/News/2005/09diabetes.asp).
As per data provided by US Census Bureau, Population Estimates, 2004 and US Census Bureau, International Data Base, 2004, further study is needed regarding role of geographical variables, particularly longitude and latitude. Western lifestyle is the fast emerging as the biggest threat contributing to the sharp rise in the incidence of Diabetes in India. This is the result of cocacolonization or mcdonaldisation of life styles. Much has been said about the socio-economic changes sweeping across India and the effect it is having on the population. Prevalence of diseases hitherto considered "rich man's disease", are disturbingly on the rise across all categories of society. One of the most morbid among these is Type 2 Diabetes Mellitus. The cost of treatment of this disease per se and its accompanying complications can ruin families. The median annual direct medical cost for patient with Type 2 Diabetes Mellitus without complications was Rs. 14,507/(Bhaskaran et al. 2003).

\section{Different Types of Diets as per Religious Believe}

According to Srimad Bhagabat Gita, persons are of three dispositions- Satvic, Rajsic and Tamsic. Foods which promote longevity, intelligence, vigor, health, happiness and cheerfulness, and which are juicy, bland, sustaining and naturally agreeable are dear to the satvic (virtuous, gentle and those endowed with goodness) type of person. Foods, which are bitter, acidic, salty, over hot, pungent, dry and burning and which cause suffering, grief or sickness, are dear to the 'Rajsic' type of persons. Foods which are half cooked or half ripe, insipid, putrid, stale and polluted, and which are impure too, are dear to persons of a 'Tamsic' disposition. Rajsic (endowed with passion) and tamsic (malignant, wicked) are the two lower categories of humans. Islam and Christianity grades food according to its source and quality- some foods are considered pious and some forbidden.

\section{Yoga and Food}

Yoga is a healthy life-style pattern widely used in India, as one of her traditional heritage having immense role in mind and disease control. According to the science of yoga, a person who has not controlled his sense organ of taste cannot control his other sense organs. Human body has two main mechanisms, one that nourishes the 
body and the other that cleanses the body by eliminating the remaining refuse. By taking excess food, life span decreases (http: //www.abc-ofyoga.com/beginnersguide/yogasystem.asp). The subjects under consideration, therefore, are: what to eat, how much to eat, when to eat and how to eat. Adequate quantity of food shall be taken only once a day preferably at daytime. Other meals should be small. There is a well-known saying, "Those who eat only once are Yogis, and those who eat twice always remain happy and those who eat thrice remain acutely diseased". Eating between meals be stopped. One major meal and one or two small refreshments are good enough for the body. Ayurved prescribes: "When urine and stool have been properly eliminated, when mind is at peace, elements are balanced, stomach is free of wind, body is light, cognitive sense organs are efficient, and appetite is there, only then may you take food!" Food should be taken one hour after moderate or severe exercise. If good nutritious food is not eaten the right way, the body cannot derive full benefit from it (Bhattacharya 1977).

\section{Effects of Eating Less}

Clinical studies involving different species of animals have shown that eating less (caloric restriction or $\mathrm{CR}$ ) reduces the risk of Cancer, Diabetes, Stroke and Heart Disease. Larsen (2004) reported a study of 18 volunteers who had been practicing $\mathrm{CR}$ and compared the results to 18 people who were eating a normal diet for an average of six years while performing identical activities. The members of the CR group were found to have significantly lower blood pressure and formation of atherosclerotic plaque in their arteries with lower levels of triglycerides, cholesterol and C-reactive protein. This leads to reduce risk of Stroke, Heart failure and Other Heart Diseases, Hypertensive Nephropathy, Cancer and Type 2 Diabetes.

However, eating less can result in nutrient deficiencies (Larsen 2004). Das et al. (1984) showed that the undernourished had lower levels of plasma lipids and a favorable distribution of cholesterol among the lipid fractions from the point of view of vulnerability to development of atherosclerosis. Sanders et al. (1986) showed that with a low fat intake the difference in effects of omega-3 and omega- 6 fatty acids were marginal. Asgary et al. (2000) reported a study with fifty healthy 30-60 year-old men intending to fast during the holy month of Ramadan. Results showed that the malondialdehyde (MDA), Triglycerides (TG) and Cholesterol levels decreased significantly during Ramadan. The levels of Fasting Blood Sugar (FBS) decreased too, but this reduction was not significant. The level of Conjugated Dienes (CDs) was increased significantly. Since MDA was significantly decreased during Ramadan, it seemed that fasting for a month might have preventive effects on atherosclerosis, considering that LDL-oxidation played an important role in the production of atherosclerotic plaques.

High cholesterol levels can lead to heart disease. ADA recommends that in a diabetic Low Density Lipoprotein (LDL) cholesterol should be below 100mg/dl, triglycerides below 150-mg/dl and High Density Lipoprotein (HDL) cholesterol above $40 \mathrm{mg} / \mathrm{dl}$. It is reported that an intake of fat as per ADA recommendation is not harmful to Indian Rural diabetic particularly living in Bengal (Mitra and Bhattacharya 2005 and 2006a).

\section{Effects of Low-Fat, High-Carbohydrate Diet}

A person on a low-fat, high-carbohydrate diet utilizes the fatty acid synthetic pathway extensively; this pathway requires citrate to leave the mitochondria to generate malonyl-CoA. The resultant high concentration of malonyl-CoA inhibits the activity of the enzyme that is the gateway to fatty acid oxidation. It is for this reason that extreme low-fat diets do not result in weight loss nearly as fast as one might expect. The burning of excess fat is actually inhibited by the high carbohydrate intake. In persons with low body fat and good lean mass, high carbohydrate intake spares the use of fatty acids and the medium chain fatty acids that are otherwise so quickly used for energy, may accumulate above "normal" in membranes (Chaudhuri 1988).

\section{Diet of Diabetics}

Diets prescribed for diabetics show dramatic changes after the discovery of insulin. Diets in the pre-insulin era consisted of a very low carbohydrate content, as carbohydrate was believed to be the offender. In insulin-dependent diabetics, the carbohydrate content was reduced to $10-20 \mathrm{gm} /$ day. The fat and protein content of the diet was increased as shown in Table 1 
(Showing Optimal Dietary Compositions of Indian Diabetics) (Chandalia and Sheth 1987). Such diets were found to initiate numerous complications. Diabetic diets in the post-insulin era derived $40 \%$, $20 \%$ and $40 \%$ of their calories from carbohydrates, proteins and fats respectively (Kahn and Weir 1996). Currently prescribed diabetic diets are high carbohydrate, high fibre and low fat diets. The present day diabetic diets derive 50 - $60 \%$ of their calories from carbohydrates, 15-20\% from fats and rest from proteins (Macrae et al. 1993). Majority of Indians are lacto-vegetarian and the diets are high in carbohydrates and low in fats and proteins (Swaminathan 1990). The amount of saturated fats is usually half of the total fat intake.

\section{Recommended Dietary Intake as per ADA}

American Diabetes Association dietary recommendations for persons with Diabetes and persons prone to Diabetes (ADA, 1987) are:

Calories: Should be prescribed to achieve and maintain a desirable body weight.

Carbohydrate: Ideally should comprise 55$60 \%$ of the calories, with the form and amount to be determined by individual eating patterns and blood glucose and lipid responses. Unrefined carbohydrates should be substituted for refined carbohydrates to the extent possible, modest amounts of sugars may be acceptable as long as metabolic control and desirable body weight are maintained.

Protein: The recommended dietary allowance of $0.85 \mathrm{~g} / \mathrm{kg}$ body weight for adults is an appropriate guide for those with Diabetes. Some reduction in protein intake from previously high consumption levels may help prevent or delay the onset of the renal complications of Diabetes.

Fat/Cholesterol: Should comprise $£ 30 \%$ of total calories, and all components should be reduced proportionately. Replacement of saturated with polyunsaturated fat is desirable to reduce cardiovascular risk. Cholesterol should be restricted to $£ 300 \mathrm{mg} / \mathrm{day}$ to reduce cardiovascular risk.
Alternative sweeteners: Both nutritive and non-nutritive sweeteners are acceptable in Diabetes management.

Sodium: Should be restricted to $1000 \mathrm{mg} / 10000$ $\mathrm{kcal}$, not to exceed $3000 \mathrm{mg} / \mathrm{day}$, to mini-mize symptoms of Hypertension. Severe sodium restriction may, however, be harmful for persons whose Diabetes is poorly controlled and for those with postural hypotension (low blood pressure and consequent dizziness when first standing up) or fluid imbalance.

Alcohol: Should be used in moderation and may need to be restricted entirely by persons with Diabetes and insulin induced hypoglycemia, neuropathy, poor control of blood sugar, blood lipids, or obesity.

Vitamins/Minerals: Should meet recommended levels for good health. Supplements are unnecessary for persons with Diabetes except when caloric intake is exceptionally low or the variety of foods consumed is limited. Calcium supplements may be necessary under special circumstances.

One might speculate that a diet low in carbohydrate would be effective in reducing hyper-glycaemia in Type 2 diabetic patients. This, however, is not true since low carbohydrate diets decrease proinsulin synthesis and insulin secretion and result in diminished peripheral responsiveness to insulin. A more effective approach is to provide relatively good quantities of complex carbohydrates that are digested and absorbed slowly so that the rate of glucose delivery into the extra-cellular space is not excessive and rapid, but rather modest and sustained, thereby giving endogenous insulin a diminished task and a longer time to effect glucose disposal (Kahn and Weir 1996). High fiber diets and guar gum have been used in Type 2 Diabetes and diabetics in general to decrease and delay carbohydrate digestion and absorption (PerHenrik Group et al. 1993). The human body contains mostly water, yet the fat (lipids) in the food must be moved throughout the body. Hence, body adopts various emulsifying strategies using cholesterol, lecithin, and bile and forms complexes

Table 1: Optimal Dietary Compositions of Indian Diabetics (Chandalia and Sheth, 1987)

\begin{tabular}{lcccccc}
\hline Diet & $\begin{array}{c}\text { Starch \& } \\
\text { other } \\
\text { polysacharides }\end{array}$ & $\begin{array}{c}\text { Sugar \& } \\
\text { dextrins }\end{array}$ & $\begin{array}{c}\text { Total } \\
\text { carbohydrates }\end{array}$ & Fat & Protein & Alcohol \\
\hline Diabetic Diets in India & $50-55 \%$ & $5-15 \%$ & $60-65 \%$ & $20-25 \%$ & $15 \%$ & $0-5 \%$ \\
\hline
\end{tabular}


with the lipids, initially very-low density lipoproteins (VLDL), then to LDL and finally to HDL. The relative quantity of the later in the blood is a fair measure of the efficiency with which fat transfer has occurred, and is thus a positive indicator for the prevention of fat deposition in the blood vessels (Ornish 1996). Researchers examined the long-term relationship between different types of dietary fat and the risk of Type 2 Diabetes and concluded that trans-fatty acids were responsible for the increased prevalence (Salmeron et al. 2001; Clandinin and Michaelann 2001). This leads to reduced intake of Vanaspati by Indians and replacement to traditional oils like mutard oil, coconut oil and ghee as oil mediums (http: //www.shirleys-wellness-cafe.com/ coconut.htm;. http://www.mercola.com/2001/jul/ 28/coconut_health.htm; Singh et al. 1996; Lip et al. 1995; Mitra 2002; Enig 2006)

\section{Effects of Fish Oil}

Prevalence of Diabetes is less in Eastern belts of India compared to other sectors. Not only is India a vast and heavily populated country, but also the people who live here are ethnically heterogeneous. This heterogeneity is manifested in significantly different religions, communities, castes, cultures, languages (18 major languages and more than 200 dialects) and food habits, life styles and in their genetic endowment. It would be true to say that India has more diversity than the whole of Europe and this diversity must be taken into account when planning any program for Diabetes Care in India. Moreover, the ruralurban divide between the people must also be taken into account. Around $70 \%$ of the people live in rural areas and $30 \%$ in urban surroundings. There is an ongoing rural to urban shift in the population. Even in the so-called urban milieu, one must consider the differences between those living in major cities and those living in smaller towns. It is rarely appreciated that there is a significant diversity amongst people living in rural, semi-urban and urban areas. Whilst the ultimate goals of a Diabetes care program may be the same, the differences and diversity must be taken into account when drawing up specific plans and guidelines, which will be put into effect in order to achieve the objectives of the Diabetes Care Program. Diabetes Epidemiological Studies of Greenland Eskimos revealed that they consumed high levels of omega- 3 products in the form of Eicosa Pentaenoic Acid (EPA) and Docosa Hexaenoic Acid (DHA), primarily in the fat of seals and coldwater fish and the component in fish that was most responsible for the beneficial effect of lowering of serum lipids was in the oils of the fish rather than in the protein or carbohydrate (Bang et al. 1971; Pfeiffer et al. 1962; Feldman et al. 1972; Lands 1986). Generally speaking, oils from the fish of the oceans are complex mixtures containing many fatty acids with as many as six double bonds. Nevertheless, for practical purposes, eight fatty acids can describe the composition of fish oil reasonably well. These fatty acids are namely, 14 : 0 and 16: 0,16: 1 and 18: 1 (omega-7 and omega-9), 20: 1 and 22: 1 (omega- 9 and omega-11), and 20: 5 and 22: 6 (omega-3) (Lands 1986; Chow 1992). These eight fatty acids make up $80-85 \%$ of the total fatty acids in fish oil. Since the fish cannot make either omega-3 or omega- 6 fatty acids, its tissues will have those polyunsaturated acids that it eats. Fish oil has little of omega-6 fatty acids. While science continues to confirm many health benefits of consuming omega- 3 fatty acids derived from fish, recent reports suggest both fish and fish oil supplements contain high levels of contaminants that may be harmful to humans (Sears 2003). Flax oil prepared for edible purpose serves the demand (Cunnane and Thompson 1995).

\section{Benefits of Vegetarianism}

Finally in vegetarians, factors other than the diet may also be involved in lowering the risk of heart disease, Diabetes, Obesity, Hypertension, Atherosclerosis and various conditions of Insulin Resistance. These include i) the nonsmoking and the non-alcoholic status of vegetarians, which may affect HDL-cholesterol levels, ii) their physically active lives, which may favorably alter apo-lipoproteins as well as HDL cholesterol, iii) their relatively low weights, which may decrease risks of Hypertension and Type 2 Diabetes. It is also worth noting that the reduction in risks of coronary heart disease seems to be associated with the type of vegetarian diet that is followed rather than some genetic protective effect of vegetarianism (Sacks et al. 1975; Burslem et al. 1978; Vessby et al. 1980; Lock et al. 1983; Masarei et al. 1984). Are there any special substances in the vegetarian diet, which give protection against Coronary Heart Disease and Diabetes? In India a lot of work has already been done on the role of garlic and onion in lowering blood cholesterol 
(Jain 1975; Sainani et al. 1976). Maize bran has also been shown to have a protective effect on the cardiovascular status (Gupta et al. 1987). Increase in fibre content reduces the blood sugar and cholesterol levels (Ng 1997; Mitra and Bhattacharya 2006b). Vegetarian diet is economic and ecologically balanced. Economic realities have to be taken into consideration. This includes, both, the finances to make comprehensive and acceptable Diabetes Care Services available to the people, and more importantly, the capacity of the people to afford these services. The Indian government spends around $1.2 \%$ of its annual budget on health and as communicable disease prevention and management is still an important aspect of health in India, the money routinely allocated to non communicable diseases, and especially Diabetes, is sparse. 1998 Nobel Prize winner in Economics Amartya Sen has said in the context of famines, "the root cause of starvation in famines is not the lack of food, but the capacity of the average person to buy the food", it can be said that the root cause of a failure of a Diabetes Program is not only the availability of services, but the capacity of the average person to afford these services. The per capita income of an Indian has been estimated to be Rs.15, 000 per year. In view of the significant disparity in incomes, most people earn much less than this. The 1998 World Development Report says that $52 \%$ of the Indian people live below the accepted poverty line. This is based on the rupee value vis a vis the dollar at 1985 rates. At that time, the rate was around Rs 14 to the dollar, whilst today it is around Rs 43 to the dollar. Consequently, the people who live below the poverty line estimated by economists are found to be more than $75 \%$. The Inequality Index in India is extremely high, and this again shows that although the per capita income may be reported as Rs. 15,000 per year, more than three fourths of the people earn less than this. The economic realities must be taken into account when drawing up any Diabetes Care Programme. Any programme must only be available to the common people, but must also be accessible and affordable to them (http: //www.diabetesindia. com/diabetes/itfdci.htm).

\section{CONCLUSION}

Exact cause of increase prevalence of Diabetes in persons of Indian origin is unknown. Nature and nurture, both may have a role. While we have a little to do, at present with nature, we can definitely modulate nurture for desirable results. Dietary control in Insulin Resistance, intake of culturally acceptable yet diabetic preventive food and not encouraging sedentary habits help to reduce the prevalence of Diabetes and is most beneficial in Indian context, as it is cost-befitting.

\section{REFERENCES}

ADA 1987. Nutritional Recommendations and Principles for People with Diabetes Mellitus. Diabetes Care, 23(1): 1-9.

Anonymous 2002. Obesity in Childhood Can Lead to Diabetes. Fitness Spectrum, The Tribune dated 21.4. 2002

Asgary S, Aghaei F, Naderi GA, Kelishadi R, Gharipour M, Azali S 2000. Effects of Ramadan Fasting on Lipid Peroxidation, Serum Lipoproteins and Fasting Blood Sugar. Medical Journal of Islamic Academy of Sciences, 13: 1.

Baird J, Fisher D, Lucas P, Kleijnen J, Roberts H, Law C 2005. Being Big or Growing Fast: Systematic Review of Size and Growth in Infancy and Later Obesity. British Medical Journal, 331(7522): 929.

Bang HO, Dyerberg J, Nielsen AB 1971. Plasma Lipid and Lipoprotein Pattern in Greenlandic West-Coast Eskimos. Lancet, 1: 1143-1146.

Bhaskaran VP, Rau NR, Acharya S, Raj R, Chinnappa S M, Koshy AT 2003. Study of the Direct Costs Incurred by Type-2 Diabetes Mellitus Patients for Their Treatment at a Large Tertiary-Care Hospital in Karnataka. Indian Journal of the Academy of Hospital Administration, 15(2): 7 -12.

Bhattacharya S 1977. Chirangeebee Banoushadhi, $1^{\text {st }}$ volume. Calcutta: Ananda Publishers Private Limited

Burr ML, Sweetman PM 1982.Vegetarianism, Dietary Fibre and Mortality. American Journal of Clinical Nutrition, 36: 873-877.

Burslem J, Schonfeld G, Howald MA, Weidman SW, Miller JP 1978. Plasma Apoprotein and Lipoprotein Lipid Levels in Vegetarians. Metabolism, 27: 711-719.

Chandalia HB, Sheth PS 1987. Conquest of Diabetes. Research Society, Grant Medical College.

Chandigarh Tribune, on-line Edition, Thursday, July 14, 2005, Chandigarh, India (2005).

Chaudhuri SK 1988. Concise Medical Physiology. $1^{\text {st }}$ Rdition. Calcutta: New Central Book Agency.

Chow CK 1992. Fatty Acids in Foods and Their Health Implications. New York, Marcel Dekker Inc.

Clandinin M T, Michaelann S Wilke 2001. Do Trans Fatty Acids Increase the Incidence of Type 2 Diabetes? American Journal of Clinical Nutrition, 73(6): 1001-2.

Cunnane SC, Thompson LU 1995. Flaxseed in Human Nutrition. Champagne, AOCS Press.

Das S, Tripathy BB, Samal KC, Panda NC 1984. Plasma Lipids and Lipoprotein Cholesterol in Undernourished Diabetic Subjects and Adults with Protein Energy Malnutrition. Diabetes Care, 7: 579-86.

Diabetes Increasing Across The State. Retrieved from http: //www.mykerala.com/n/health.shtml on 28.4 . 2006. 
Diabetes Risk Score Developed. Retrieved from http: // www.chennaionline.com/health/News/2005/09dia betes.asp on 12.5.2006.

Dilman VM 1989. The Grand Biological Clock. Moscow: Mir Publishers.

Enig MG Coconut Oil - Health and Nutritional Benefits. Retrieved from http: //www.shirleys-wellnesscafe.com/coconut.htm on 16.01.2006.

Ernst E, Pietsch L, Matrai A, Eisenberg J 1986. Blood Rheology in Vegetarians. British Journal of Nutrition, 56(3): 555-560.

Feldman SA, Ho KJ, Lewis LA, Mikkelson B and Taylor CB 1972. Lipid and Cholesterol Metabolism in Alaskan Artic Eskimos. Archives of Pathology and Laboratory Medicine, 94: 42-58.

Fisher M, Levine PH, Weiner B 1986. The Effect of Vegetarian Diets on Plasma Lipid and Platelet Levels. Archives of Internal Medicine, 146:1193-1197.

Ghafoarunissa 1996. Fats in Indian diets and Their Nutritional and Health Implications. Lipids, 31 (Supplement): 287-291.

Gupta OP, Bajaj S, Srivastava P, Chaurasia AK 1987. Role of Maize Bran on Cardiovascular status, Lipid Profile and Glycaemic Control in Diabetes Mellitus. Journal of Association of Physicians in India, 35(5): 353-5.

Harris SB, Zinman B, Hanley A, Gittelsohn J, Hegele R, Connelly PW, Shah B, Hux JE 2002.The Impact of Diabetes on Cardiovascular Risk Factors and Outcomes in a Native Canadian Population. Diabetes Research and Clinical Practice, 55: 165-73.

Hyderabad Emerging As Diabetes Capital of India. Retrieved from http: //news.hitavadaonline.com/ news/index.php mode $=$ single $\&$ page $=11 \& n=6546$ on 23.4.2006.

Hyderabad Has emerged As Diabetes Capital Of India: Expert Hyderabad. Retrieved from http: // news.webindia123.com/news/showdetails.asp?id $=231251 \&$ cat $=$ Health on Jan 26, 2006 .

Jain RC 1975. Effect of Dietary Garlic and Onion on Serum Lipid Profile. Lancet, 1: 1240.

Kahn CR, Weir GC 1996. Joslin's Diabetes Mellitus. New Delhi: B. I. Waverly Pvt. Ltd.

King H, Aubert RE, Herman WH 1998.Global Burden of Diabetes, 1995-2025: Prevalence, Numerical Estimates, and Projections. Diabetes Care, 21: 1414-31.

Lands WEM 1986. Fish and Human Health. New York: Academic Press Inc.

Larsen H 2004.Calorie restriction improves health. International Health News, 149. *(based on original article published on New Scientist: 12-13).

Lip GY, Malik I, Luscombe C, McCarry M, Beevers G 1995.Dietary Fat Purchasing Habits In Whites, Blacks And Asian Peoples In England. Implications for Heart Disease Prevention. International Journal of Cardiology, 48: 287-293.

Lock DR, Varhol A, Grimes S, Patsch W, SchonfeldG 1983. ApoA-I/ApoA-II Ratios in Plasma of Vegetarians. Metabolism, 32: 1142-1145.

Luscombe ND, Clifton PM, Noakes M, Parker B, Wittert G 2002.Effects of Energy-Restricted Diets Containing Increased Protein on Weight Loss, Resting Energy Expenditure, and The Thermic Effect of Feeding in Type 2 Diabetes. Diabetes Care, 25: 652-657.

Macrae R, Robinson RK, Sadler MJ 1993. Encyclopedia of Food Science, Food Technology and Nutrition. $2^{\text {nd }}$ Volume. London: Academic Press.

Maliyannar I, Shrinivas BR 2004.Cancer in South Karnataka and Its Paradoxical Relation to Diabetes Mellitus. Indian Journal of Clinical Biochemistry, 19(1): 6-9.

Masarei JRL, Rouse IL, Lynch WJ, Robertson K, Vandongen R, Beiling LJ 1984. Vegetarian diets, lipids and cardiovascular risk. The Australian \& New Zealand Journal of Medicine, 14: 400-404.

Mitra A 2002. Neutraceuticals for Control of Non-Insulin Dependent Diabètes Mellitus. IIT Kharagpur, $\mathrm{Ph}$. D. Dissertation.

Mitra A, Bhattacharya D 2005. Effects of Overall Consumption, Dietary Patterns, Cooking, on Patients Suffering From Non Insulin Dependent Diabetes Mellitus. Journal of Interacademicia, 9(4): 635-642.

Mitra A, Bhattacharya D 2006a. Effect of Fatty Substances on Health particularly to Patients Suffering from NIDDM and Dyslipidaemia. Journal of Interacademicia, 10(1): 74-85.

Mitra A, Bhattacharya D 2006b. Role of retrograded starches particularly rice containing retrograded starches in non-insulin dependent diabetes mellitus. All India Seminar on Advances in Agro-Processing And Rural Empowerment. Agriculture Engineering Division, The Institution of Engineers (India), West Bengal State Center, 8 Gokhale Road, Kolkata 700 020. Kolkata, Feb 17-18.

Misra A, Pandey RM, Devi JR, Sharma R, Vikram NK, Khanna N 2001. High Prevalence of Diabetes, Obesity and Dyslipidaemia in Urban Slum Population in Northern India. International Journal of Obesity Related Metabolic Disorder, 25: 1722-1729.

Mohan V, Vijayaprabha R, Rema M 1996. Vascular complications in long-term south Indian NIDDM of over 25 years' duration. Diabetes Research and Clinical. Practice, 31: 133-140.

Mohan V, Shanthirani CS, Raj DPG, Sastry NG, Saroja R 2001. Chennai Urban Population Study (CUPS No. 4).: Intra-urban Differences in the Prevalence of the Metabolic Syndrome in Southern India - the Chennai Urban Population study (CUPS No. 4). Diabetic Medicine, 18(4): 280-287.

Mohan V, Shanthirani CS, Mohan DRD, Unnikrishnan RI, Datta M 2006. Mortality Rates Due to Diabetes in a Selected Urban South Indian Population - The Chennai Urban Population Study [CUPS -16]. Journal of Association of Physicians in India, 54: 113-117.

$\mathrm{Ng}$ TKW 1997. Dietary fat and fibre intakes of Malaysian adults: issues and implications when 'western targets' are set as dietary goals. Malaysian Journal of Nutrition, 3: 137-147.

Ornish D 1996. Program for Reversing Heart Disease. New York: Ivy Books.

Per-Henrik Group, Antti A, Svante S, Lief G 1993. LongTerm Effects of Guar Gum in Subjects with NonInsulin-Dependent Diabetes Mellitus. American Journal of Clinical Nutrition, 58: 513-518.

Peifer JJ, Janssen F, Muesing R, Lundberg WO 1962. The lipid depressant activities of whole fish and their component oils. Journal of American Oil Chemistry Society, 39: 292-296. 
Raheja BS, Talwalkar NG, Suttarwalla SK 1970. Ischaemic Heart Disease in Diabetes. Journal of Association of Physicians in India, 18(2): 261-7.

Ramachandran A, Snehalatha C, Kapur A, Vijay V, Mohan V, Das AK, Rao PV, Yajnik CS, Prasanna KKM, Nair DJ 1990. High Prevalence of Diabetes and Impaired Glucose Tolerance in India: National Urban Diabetes Survey Diabetes Metabolism Review, 6: 125-146.

Ramachandran A, Snehalatha C, Kapur A, Vijay V, Mohan V, Das AK 2001. For Diabetes Epidemiology Study Group in India (DESI). High Prevalence of Diabetes and Impaired Glucose Tolerance in India: Nationa Urban Diabetes Survey. Diabetologia, 44: 10941101.

Ramachandran A, Snehalatha C, Vijay V 2003. Explosion of Type 2 Diabetes in the Indian subcontinent. International Diabetes Monitor, 15(5): 1-6.

Ramaiya KL, Kodali VR, Alberti KG 1990. Epidemiology of diabetes in Asians of the Indian subcontinent. Diabetes Metabolic Review, 6: 125-46.

Reddy NK, Kumar DN, Rayudu NV, Sastry BK, Raju BS 2002. Prevalence of Risk Factors For Coronary Atherosclerosis in a Cross-Sectional Population of Andhra Pradesh. Indian Heart Journal, 54(6): $697-$ 701

Sacks FM, Castellik WP, Donner A, Kass FH 1975 Plasma Lipids and Lipoproteins in Vegetarians and Controls. The New England Journal of Medicine, 292: 1148-1151.

Sainani GS, Desai DB, More KN 1976. Onion, Garlic and Atherosclerosis. Lancet, 1: 575.

Salmeron J, Hu FB, Manson JE 2001. Dietary Fat Intake and Risk of Type 2 Diabetes in Women. American Journal of Clinical Nutrition, 73: 1019-26.

Sanders TAB, Oakley FR, Miller GJ, Mitropoulous KA 1985. Influence of N-6 Versus N-3 Polyunsaturated Fatty Acids in Diet Low in Saturated Fatty Acid
Decreases During Long Term Compliance with a Lipid Lowering Diet. Journal of Internal Medicine, 59: 249-258.

Sears B 2003.The Omega Rx Zone: The Miracle of the New High-Dose Fish Oil. New York: McGraw-Hill Publication Division.

Singh RB, Niaz MA, Ghosh S, Beegom R, Rastogi V, Sharma JP, Dube GK 1996. Association Of Trans Fatty Acids(Vegetable Ghee) and Clarified Butter(Indian Ghee) Intake with Higher Risk of Coronary Artery Disease in Rural and Urban Populations with Low Fat Consumption. International Journal of Cardiology, 56: 289-298.

Swaminathan M 1990.Food and Nutrition. Volume-2. Bangalore, Bangalore Printing and Publishing Company.

Tamil Recipes On-line. Retrieved from http: //www. kuttyjapan.com/tamilrecipes/idly.asp on 20.4.2006.

The System of Yoga - Yoga Breathing, Poses, And Meditation. Retrieved from http: //www.abc-of-yoga. com/beginnersguide/yogasystem.asp on 12.2.2006.

The Indian Task Force on Diabetes Care In India. Retrieved from http: //www.diabetesindia.com/ diabetes/itfdci.htm on 27.4.2006.

Vessby B, Boberg J, Gustafsson IB 1980. Reduction of High Density Lipoprotein Cholesterol and Apolipoprotein A-I Concentrations by a Lipid Lowering Diet. Atherosclerosis, 35: 21-27.

Wahrenberg Hans, Hertel K, Leijonhufvud BM, Persson LG, Toft E, Arner P 2005. Use of Waist Circumference to Predict Insulin Resistance: Retrospective Study. British Medical Journal, 330: 1363-1364

Western Lifestyle Leading To Rise In Diabetes In India. Retrieved from http: //www.dailyexcelsior.com/ 01may07/inter.htm on 28.4.2006. 